\title{
KINESIOLOGIC AND METABOLIC RESPONSES OF PERSONS WITH CEREBRAL PALSY TO SUSTAINED EXERCISE ON A PETRA RACE RUNNER
}

\author{
Ruairí O Donnell, Joeri Verellen, Peter Van de Vliet and Yves Vanlandewijck
}

\author{
Department of Rehabilitation Sciences, Faculty of Kinesiology and Rehabilitation Sciences, \\ Katholieke Universiteit Leuven, Leuven, Belgium
}

\begin{abstract}
The purpose of this study was to investigate if the performance and metabolic response of cerebral palsy (CP)-athletes to a sustained submaximal exercise on a Petra Race Runner (PRR) was confirm their CP-ISRA classification. Furthermore, the impact of fatigue on the quality of propulsive movement was assessed. Nine athletes with CP from CP-ISRA classes CP1 up to CP6 took part in a 12 minute Cooper Test using a PRR. Changes in heart rate, blood lactate and pace per minute were monitored throughout the test. Results showed that heart rate rose immediately to high levels (a mean of over 160 after the first minute), and was sustained at this level through the test. Blood lactate concentration increased in a curvilinear pattern, but was subject to much inter-individual difference. Analysis from video recordings showed that participants maintained a very consistent movement pattern (step-length, stride frequency) as they became fatigued in the later stages of the Cooper test. The results clearly demonstrated the limitations of using the CP-ISRA classes for PRR competition. No evidence was generated showing an adverse impact of sustained submaximal PRR on the quality of propulsive movement.
\end{abstract}

KEYWORDS: Petra bike, Cerebral palsy, Cooper test, Heart rate, Paralympics.

\section{INTRODUCTION}

Several authors have commented on the need for appropriate modes of exercise for persons with CP (Rimmer, 2001; Cooper et al. 1999), and this is especially important for people with more severe $\mathrm{CP}$.

Traditional opposition to the use of strength and conditioning training for people with $\mathrm{CP}$ stemmed from the work of Berta Bobath (1990). Bobath advised against the use of strenuous exercise by persons with upper motor neuron lesions such as $\mathrm{CP}$ or stroke. Researchers have since challenged this view. Resistance training has been shown to increase strength in children with $\mathrm{CP}$ without an adverse effect on muscle tone (Dodd, Taylor and Damiano, 2002; Damiano 2006). Other studies have shown no adverse effect on muscle tone immediately after resistance training (Fowler, Ho, Nwigwe and Dorey, 2001) and after a 6-week training period (Morton, Brownlee and McFadyen, 2005). These studies have investigated the response to resistance training and the response to aerobic exercise has not yet been described. However, this research does support the idea that persons with $\mathrm{CP}$ can safely participate in physical conditioning. Further support is garnered from the observations of clinicians who are involved in organising sport for persons with CP (Chappel, 2002; Richter, Gaebler-Spira and Mushett, 1996; Wind, Schwend and Larson, 2004).

The Petra RaceRunner (PRR) holds considerable potential as a means of exercise for people with CP. The device also known as a Petra Bike was developed in Denmark by Connie Hanson. The PRR consists of a 3-wheeled frame, with handlebars and saddle similar to a tricycle (see Figure 1). There is also a trunk support that the user can rest their anterior trunk on. Rather than using a pedalling system, the user sits on the saddle and propels themselves forward by contact of his/her feet on the ground. For some people with $\mathrm{CP}$, it is easier to do this stepping movement of the legs than to pedal a traditional bicycle. The PRR has been used by 
people with various types of $\mathrm{CP}$ including those with more severe $\mathrm{CP}$. The PRR has been used with various goals: as a means of locomotion, as a form of health related exercise, and as a new event in track athletics. Thus far, competition in Petra-running has classified athletes into the standard classes used by the Cerebral Palsy International Sport and Recreation Association (CP-ISRA). This classification system uses 8 classes and was developed before Petra-running was developed.

Figure 1. A Petra Race Runner in action on the athletic track.

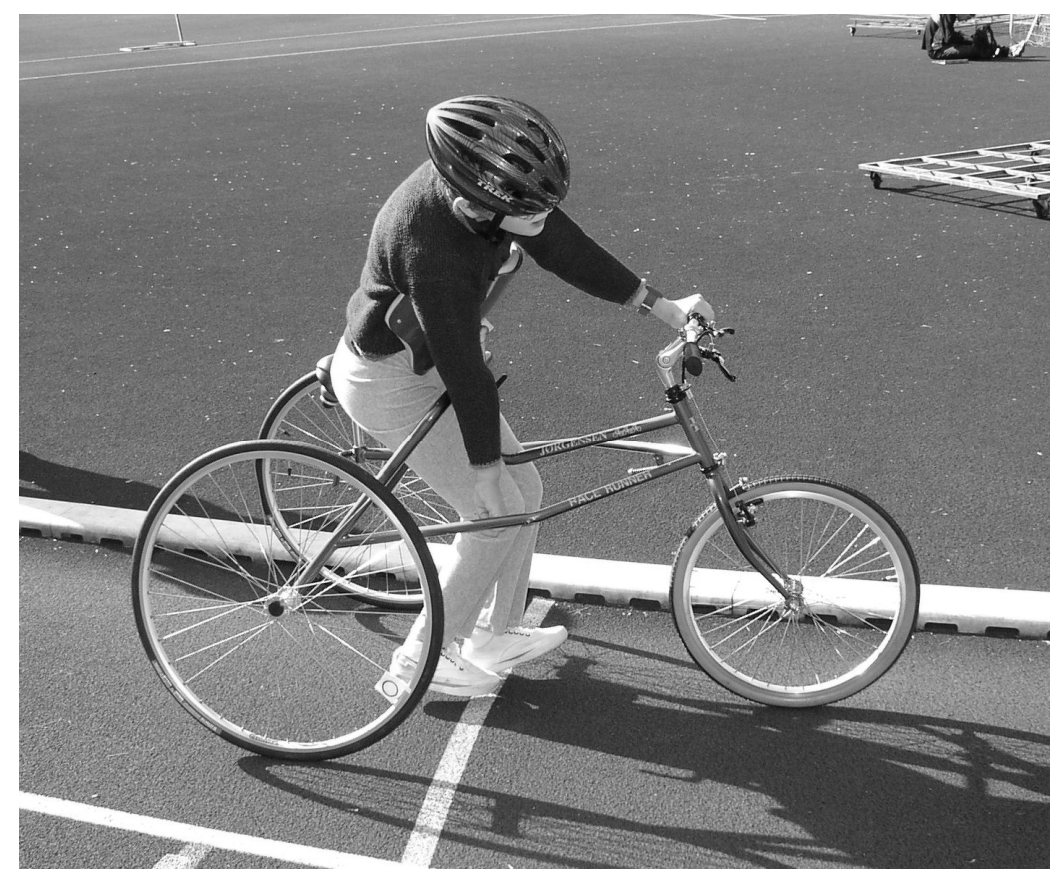

The purpose of this research project was to investigate how persons with $\mathrm{CP}$, including those with more severe $\mathrm{CP}$, respond to the activity of Petra-running. As the sample group included athletes from various CP-ISRA classes, it was possible to compare the response and performance of athletes with different activity limitations. The first research question investigated the metabolic response of athletes with $\mathrm{CP}$ to sustained exercise on a PRR, and whether there is a different response and performance for athletes with different functional potential. Related to this, the first hypothesis tested was: Performance in a Cooper test is dependent on the functional potential of the athletes (as graded by CP-ISRA class). Testing the first hypothesis will show if the current CP-ISRA classification system could serve as a tool to classify future PRR athletes? The second research question investigated the kinesiological response of athletes with $\mathrm{CP}$ to sustained exercises on a PRR. Related to this, the second hypothesis tested was: There is a change in kinesiological measures (step-length, stride-frequency) and pace as athletes become fatigued in the later part of the Cooper test. Testing the second hypothesis will clarify if PRR has an adverse effect on the quality of propulsive movement due to fatigue.

\section{METHOD}

A Cooper Test was selected as the means to examine the research questions, as this test closely mirrors the effort during a long distance race i.e. a sustained submaximal effort over a prolonged time period... The Cooper Test is a test where participants cover as much distance as they can in 12 minutes (Cooper and Storer, 2001). A test of this duration is sufficiently long to monitor changes associated with fatigue. Also, all participants were familiar with the Cooper 
Test, as they had previously performed the test as part of club training.

\section{Participants}

The participants in this study were all members of a Petra-running club in the Flemish part of Belgium, and therefore were experienced in Petra-running. They all had a diagnosis of $\mathrm{CP}$ and had each been previously classified under the CP-ISRA rules for classification in sports events. All participants were described in terms of the type of cerebral palsy (spastic, athetoid, dystonic or ataxic), and the parts of body affected (diplegia, hemiplegia or quadriplegia).

The characteristics of the participants are given in Table 1. The participants ranged in age from 14 to 33 years and had a mean age of 23.6 years ( \pm 9.2 years).

All athletes invited had been involved in Petra-running for at least one year. This ensured that they were skilled in the action of Petra-running. Of 11 people invited (which is the total PRR population in the Flemish part of Belgium), 9 agreed to attend. All adult participants had signed a consent form and participants under 18 had a form signed by a parent. The testing took place on a standard 8lane athletics track with a tartan surface. Participants used the PRR that they were familiar with using during training and competition. The coach of the club was present during the testing session, and assisted each participant in getting on to the PRR. He also ensured that the PRR was set up appropriately for each participant (saddle height, position of chest support). A Polar Heart Rate Monitor was worn by participants during their exercise test (Polar Heart Rate Monitors, Finland). The monitor was attached to the handlebars, so that it could be read by a researcher walking alongside the PRR.

\section{Test Protocol}

Participants were given instructions before starting the test. The instructions were to start running / walking, and continue so as to go as far as possible in the 12 minutes allowed. No warm-up was used, as a test of this duration allows participants to warm up over the first few minutes. Also, for some of the participants, any workload / distance covered on the PRR before the test would start to induce fatigue. A white plastic disc, $4.5 \mathrm{~cm}$ in diameter, was attached to the right rear wheel of the PRR before the test. This was used as a reference point during the video analysis. The test started at the start of the straight on the track. This allowed participants to accelerate to a steady pace before encountering the bend on the track. The participants undertook the test individually, and the research team travelled either alongside or behind the participant so as not to create a pacing effect.

The participant was filmed from a wheeled device at a standardised distance to the outside of the PRR. Movements from the participants were filmed and analysed in the sagittal plane. Film footage was taken for the whole of the first minute, and then for the last 15 seconds of minutes 2 to minute 12 . At each 30-second interval, a research assistant checked the display of the heart rate monitor and recorded the value. At each 1-minute interval, the location of the PRR on the track was labelled with adhesive tape on the ground. The distance covered by the participant during each minute interval was then measured by a pair of research assistants using a standard athletics $50 \mathrm{~m}$ measuring tape.

Blood lactate samples were taken immediately before starting the test, after 4 minutes, after 8 minutes, and at the end of the test, using a LactatePro testing kit (Samcon, Belgium). This testing required the collection of a drop of blood from the ear lobe of the participant. At the 4-minute and 8-minute time points, the PRR was slowed to a standstill by the researcher to allow collection of the blood sample. The timekeeper stopped the clock while the participant was stationary. Once the blood sample was taken, the participant resumed the test.

\section{Video Analysis}

The original film footage was transferred onto one VHS video cassette, which contained an on-screen timer giving minutes, seconds and frame number (25 frames per second). A standard video player which 
allowed frame by frame advancing was used to analyse the video. Footage from the last 15 seconds of each minute of the test was analysed for all participants.

\section{STRIDE FREQUENCY}

For each 15-second segment, the first 4 complete step-cycles were analysed. The average value for the duration of one stride was calculated. This was then used to calculate a value for stride frequency, expressed in strides per minute. The analysis produced a value for stride frequency for each minute of the test. This data was compiled for all participants.

\section{STEP-LENGTH}

The same segments of film were used to determine the step-length for each leg, left and right. A step was considered as beginning when the foot contacted the ground and ending when the opposite foot contacted the ground. This distance was not measured directly but was calculated from the amount of wheel revolutions of the rear wheel of the PRR that occurred between a step starting and ending. An additional factor needed for this calculation was the diameter of the rear wheel of the PRR. This was measured with a tape measure on each PRR after the testing was completed. The step-length for five subsequent steps was calculated and the average of these five values was used. The analysis produced a value for average steplength, in meters, for each leg at each minute of the test. This data was compiled for all participants.

\section{Statistical analysis}

The following analysis was performed for the first research question: Descriptive data (means and standard deviations) were calculated to describe the participants' response in terms of distance achieved, heart rate, and blood lactate level. Means and standard deviations were also calculated for descriptive comparison between subgroups: CP1-2 athletes versus CP4-6 athletes,
CP-ISRA wheelchair classes (CP1-4) versus CP-ISRA ambulant classes (CP5-6), and athletes with a diagnosis of spastic quadriplegia versus athletes with a diagnosis other than spastic quadriplegia.

The following analysis was performed for the second research question: The measures of step-length right, step-length left, stride frequency, were used for each minute of the test, for each participant. A one-way ANOVA with repeated measurements was performed. Significance level was chosen as $\mathrm{p}<0.05$.

\section{RESULTS}

The total distance covered by each participant in the Cooper test and their maximal recorded values for heart rate and blood lactate concentration are given in Table 1. The distances covered by the participants in the Cooper test ranged from $206 \mathrm{~m}$ to $1867 \mathrm{~m}$. The mean distance covered was $854 \mathrm{~m}( \pm 526 \mathrm{~m})$. The mean of the maximal blood lactate concentration of the participants was 5.0 $\mathrm{mmol} / \mathrm{l}( \pm 3.7 \mathrm{mmol} / \mathrm{l})$.

Mean values and standard deviations for distance recorded for the various sub-groups were: CP1-2 athletes $(731 \mathrm{~m}[ \pm 672])$ versus CP4-6 athletes (1008m [ \pm 278$])$,

CP-ISRA wheelchair classes $(712 \mathrm{~m}[ \pm$ 603]) versus CP-ISRA ambulant classes (1137m [ \pm 125$])$, athletes with a diagnosis of spastic quadriplegia $(447 \mathrm{~m}$ [ \pm 255$])$ versus athletes with a diagnosis other than spastic quadriplegia (1180m [ \pm 454$])$.

The response of the participants in terms of heart rate and blood lactate over the 12 minutes of the test is shown in Figure 2.

ANOVA with repeated measurements indicated no significant differences over time for the measures of step-length right, step-length left, stride-frequency, and distance covered per minute. The results of the ANOVA with repeated measurements are shown in Table 2.

The value of these measures over the 12 minutes of the test is shown in Figure 3. 
Table 1

Participant characteristics and the results of the Cooper test

\begin{tabular}{cccccccc}
\hline Participant & Descriptor & Class & Age & Gender & Distance & Max HR & Max [La] \\
& & (CP-ISRA $)$ & $($ years $)$ & & $(\mathrm{m})$ & $(\mathrm{bpm})$ & $(\mathrm{mmol} / \mathrm{l})$ \\
\hline A & Spastic Quadriplegia & CP1 & 14 & Female & 797 & 200 & 2,8 \\
B & Spastic Quadriplegia & CP1 & 14 & Female & 463 & 203 & 1,9 \\
C & Spastic Quadriplegia & CP2 & 16 & Male & 206 & 180 & 2,8 \\
D & Athetoid Quadriplegia & CP2 & 33 & Male & 1867 & 204 & 10,5 \\
E & Spastic Quadriplegia & CP2 & 17 & Male & 324 & 190 & 5,1 \\
F & Spastic Diplegia & CP4 & 19 & Female & 620 & 171 & 1,9 \\
G & Spastic Diplegia & CP5 & 29 & Female & 1130 & 175 & 8,6 \\
H & Ataxic Quadriplegia & CP6 & 36 & Male & 1015 & 127 & 1,3 \\
I & Dystonic Quadriplegia & CP6 & 34 & Female & 1266 & 203 & 9,9 \\
\hline Mean & & & 23,6 & & 854,2 & 183,7 & 5,0 \\
SD & & & 9,3 & & 525,6 & 24,8 & 3,7 \\
\hline
\end{tabular}

Figure 2. Average heart rate response and blood lactate response during the Cooper test (vertical bars indicate standard deviation).

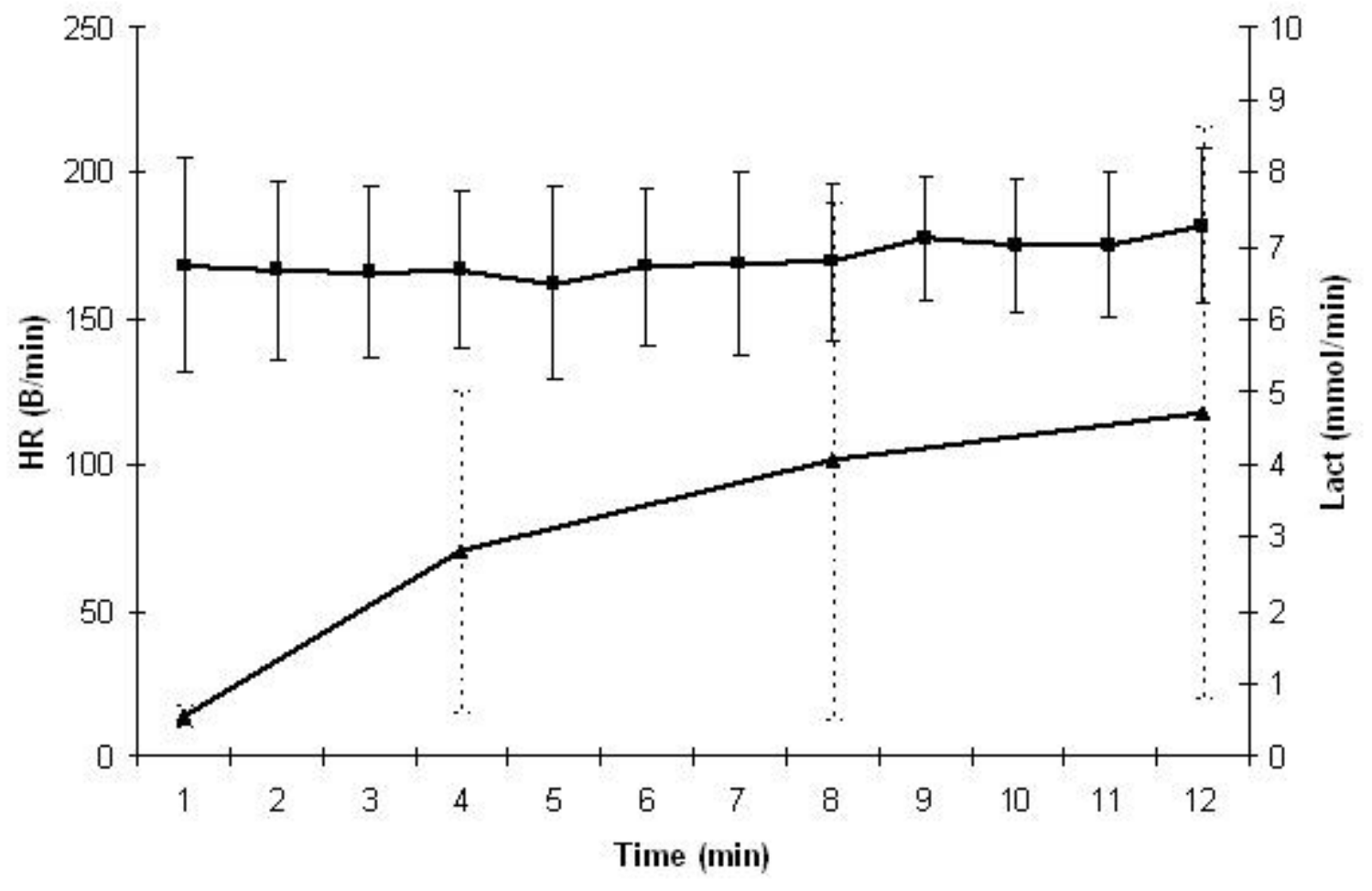


Table 2

Results of ANOVA with repeated measurements over time

\begin{tabular}{lcc}
\hline Kinesiologic parameter & F & p \\
\hline Step-length right & 0.83 & 0.61 \\
Step-length left & 0.81 & 0.63 \\
Stride frequency & 1.54 & 0.13 \\
Distance covered (per minute) & 0.94 & 0.50 \\
\hline
\end{tabular}

Figure 3. Changes in kinesiologic parameters over 12 minutes of Cooper test.

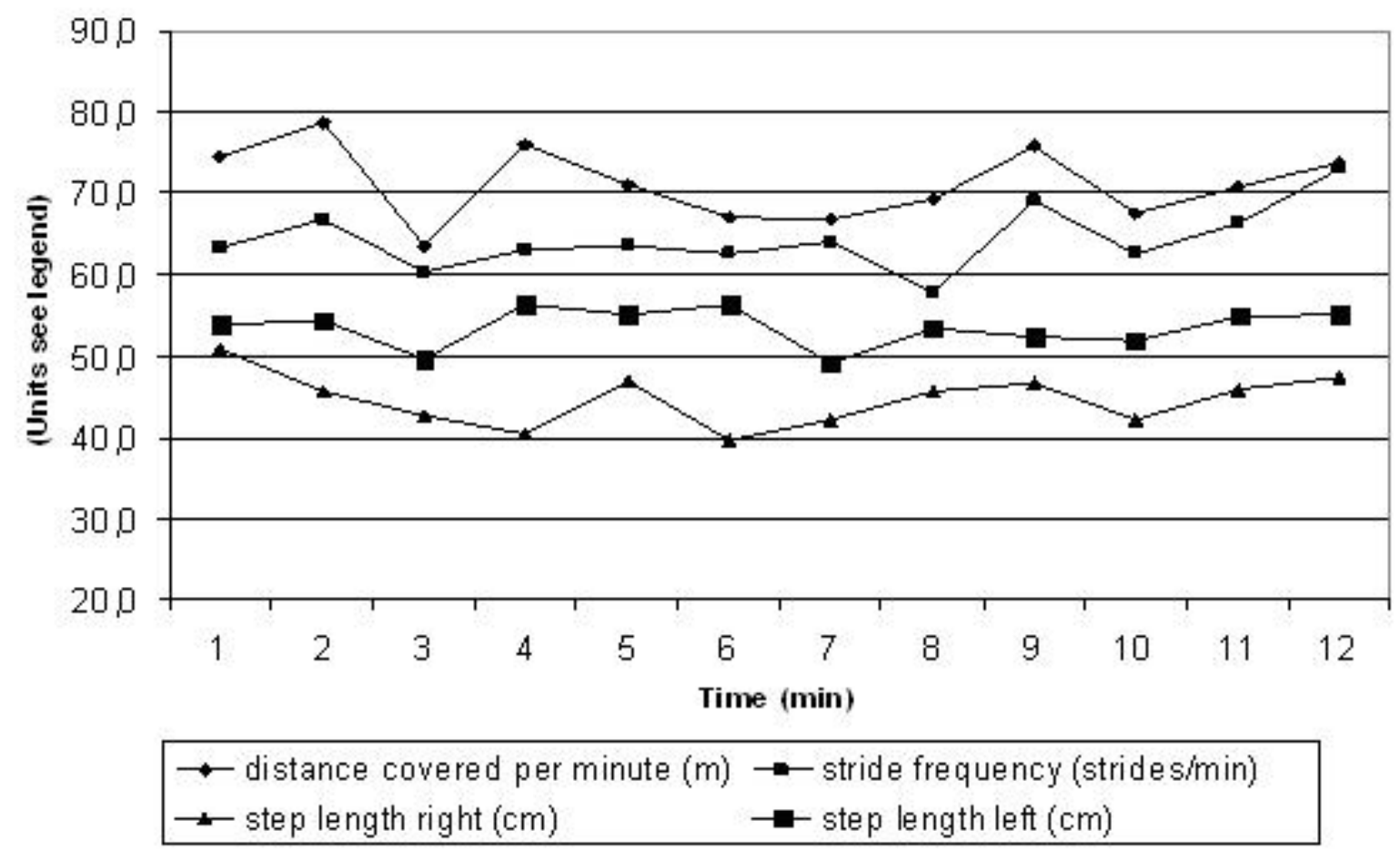

\section{DISCUSSION}

The metabolic response of these athletes to Petra-running is seen in the graph of heart rate and blood lactate concentration over the 12 minutes of the Cooper test (Figure 1). Heart rate increased immediately on starting the test, and the average value was over 160 $\mathrm{b} / \mathrm{min}$ after the first minute. Heart rate remained consistently at a high level through the test. This shows that the participants were exercising at high levels of intensity through the full duration of the test. Eight of the nine athletes responded with near maximal heart rates. Apart from athlete $\mathrm{H}$, they reached $85 \%$ or more of the predicted maximal heart rate based on age. Darrah, Wessel et al. (1999) reported that the majority of their adolescent participants recorded heart rates of over 145 $\mathrm{b} / \mathrm{min}$ while performing an aerobic choreography routine, but that this intensity was not maintained continuously during that form of exercise. This contrasts with the response during this Petra-running test, which shows a high intensity level being maintained over time.

There is a high standard deviation $( \pm 3.7$ $\mathrm{mmol} / \mathrm{l}$ ) for the maximum blood lactate 
concentration attained. This reflects a high inter-individual difference in blood lactate response amongst the 9 participants. In Figure 1 , at each successive time-point, there is an increase in the range \pm 1 standard deviation around the mean blood lactate concentration. Even with this inter-individual variation, the overall trend in figure 1 is a curvilinear increase of blood lactate concentration over time. This curvilinear pattern has been described as the normal response for able-bodied individuals (Sjodin, Schele, Karlsson, Linnarsson, and Wallensten 1982). Previous research on the exercise response of persons with $\mathrm{CP}$ has investigated their response in terms of heart rate and $\mathrm{VO}_{2}$, but without blood lactate measures (Unnithan, Clifford and Bar-Or, 1998; Hoofwijk, Unnithan and Bar-Or, 1995). One previous study did take blood lactate measures of adolescents with $\mathrm{CP}$ and described changes in these measurements before and after 6 weeks of training (Lunberg and Pernow, 1970). However, they did not investigate the pattern of blood lactate accumulation during exercise.

The comparison between sub-groups of athletes allows us to broadly support hypothesis 1 . That is, performance in Petrarunning is dependent on the level of functional potential as measured by the current CP-ISRA classification system. The mean distance achieved by athletes in the 'ambulant classes' (CP5-6) was $1137 \mathrm{~m}$, and this was clearly greater than the mean $(712 \mathrm{~m})$ for athletes in the 'wheelchair classes' (CP1-4). This difference was more pronounced when the performance of Participant D, who had an athetoid type CP, was discounted (see Table 1). There is a similar trend when looking at the performance of athletes in classes CP1-2. The performance of this sub-group was lower than for the athletes in classes CP4-6. The third trend observed was in regard to the type of $\mathrm{CP}$ which an athlete has. The athletes with spastic quadriplegia type CP (mean distance $447 \mathrm{~m}$ ) tended to record a lower distance than the athletes with other types of CP (mean distance $1180 \mathrm{~m})$.
These trends regarding performance are general and are subject to much interindividual variation. This variation is seen in athletes with a similar class or type of $\mathrm{CP}$ recording very different distances. Our results show that two athletes of the same class (CP2) recorded the highest and lowest distance in the Cooper test. Also, the single athlete with athotoid-type $\mathrm{CP}$ recorded a much higher distance than the others who had spastic-type CP (seven athletes) or ataxic-type $\mathrm{CP}$ (one athlete). This highlights how the type of tone that a person with $\mathrm{CP}$ has - spastic, athetoid or ataxic - will be a further factor influencing their performance in Petrarunning. The scale of differences between participants in the same class, and the scale by which some athletes out-performed those in higher classes, has demonstrated the limitations of using the current CP-ISRA classes for Petra-running. CP-ISRA has developed sport-specific criteria for the classification of athletes in sports such as swimming. Petra-running will need a sportspecific classification system if it evolves into a competitive sport.

Hoofwijk et al. (1995) and Unnithan et al. (1999) discuss factors which may affect the performance of people with $\mathrm{CP}$ in aerobic exercise. Firstly, people with $\mathrm{CP}$ can have a lower breathing efficiency compared to ablebodied persons. Secondly, the presence of high muscle tone can reduce venous return and this inhibits lactate clearance during exercise. Thirdly, the presence of involuntary movements and high levels of muscle co-contraction add to oxygen consumption. These three factors have been suggested to explain the lower $\mathrm{VO}_{2} \max$ recorded for children with CP. They are based on a small number of research studies, mostly involving children or adolescents with milder forms of CP. They draw attention to specific factors which could add to the metabolic demands of people with CP during Petra-running. It is important to consider the metabolic response of the athletes in this study who had lower performance in Petra-running and the implications of these findings. Two athletes were travelling at very slow speeds 
- completing less than one lap of the athletics track in 12 minutes. At the same time, their heart rates showed how intensely they were exercising (maximum values of 180 and 190 respectively). The metabolic response of these two athletes illustrates one limitation of Petra-running. Some athletes with $\mathrm{CP}$ will be working at a high intensity to propel themselves forward at any speed. There is no option of adjusting the power output needed by an athlete to propel him or herself on a PRR. This is in contrast to cycling on a tricycle or exercise bicycle. A tricycle or exercise bicycle has one significant advantage for a person with reduced power output. A tricycle can be fitted with a low gear, and this means pedals can be turned continuously by an athlete with low power output. Also, propelling a tricycle involves a closed-chain movement. Research suggests that this is a more efficient movement pattern. Most exercise bicycles have mechanisms to reduce the resistance needed to turn the pedals, which mimics the advantage of cycling with a low gear.

Training for aerobic fitness needs to be done at an appropriate intensity. Some people with CP will find Petra-running at any speed to be a high intensity activity, and thus it is not suitable for aerobic conditioning. Such individuals can consider using a tricycle or exercise bicycle for a more appropriate aerobic training stimulus. However, there are also limitations with a tricycle or exercise bicycle for this group. Some people with CP will have reduced range of movement in their legs and reduced ability to sit upright. Either of these problems can mean they cannot comfortably use a tricycle or exercise bicycle. The advantage of Petra-running is that people with reduced trunk control and reduced range of movement in their legs can participate. It is worth noting that some of the participants in this study used moulded seating in the wheelchair that they used during the day. These participants would likely not have managed to cycle a tricycle, but were able to use the PRR.

The second aim of this study was to investigate the effect of fatigue on the movement pattern of the participants while practicing Petra-running. A sustained submaximal effort test such as a Cooper test will produce considerable fatigue in the later stages. The data collected gives a snapshot of each athlete's step-length right, step-length left, stride frequency, and pace (per minute) during each of the 12 minutes of the test. This is a considerable amount of data, and should capture any overall trends that occur as athletes become fatigued. ANOVA with repeated measures of all participants does not show a significant change for these characteristics (see Figure 2 and Table 2). Hypothesis 2 states that there is a change in kinesiologic measures (step-length, stride frequency) and pace as athletes become fatigued in the later part of the Cooper test. The hypothesis is rejected on the basis of this data. These findings challenge the belief that persons with $\mathrm{CP}$ experience adverse effects to their muscle tone when they are fatigued from exercise. Although previous researchers have investigated this issue with resistance training (Fowler et al. 2001; Miller and Light, 1997), this issue has not been discussed in relation to aerobic exercise. One note of caution is advised in relation to the findings regarding kinesiologic parameters. This study only assessed for changes relating to the lower limbs. It is possible that changes in muscle tone did affect the head, trunk or arms. Further research is needed to quantify any changes that occur in these parts of the body during Petra-running.

Petra-running has the potential to become a component of physiotherapy programmes for people with CP. Blundell, Shepherd, Dean and Adams (2003) describe a new model for movement rehabilitation in children and adults with neurological problems such as CP. The three strands of this approach comprise 1) the training of motor control with skill and performance as goals, 2) the prevention of negative soft tissue adaptations, and 3 ) training for increased strength, endurance and physical fitness. Petra-running holds an obvious potential in the third strand. It can be used to improve cardiovascular fitness and is likely to improve the strength and endurance 
of leg muscles. Petra-running could play a role in the second strand of this treatment approach as well. Many persons with more severe CP use a wheelchair for part or all of the day. This group of persons are at risk of developing soft tissue shortening in the hip flexor and knee flexor muscles (Bell and Watson, 1986). One way to minimise this is to take a break from a sitting position during the day. This is often performed using standing frames or other postural management equipment. An alternative, more active way of doing this could be to do exercise on a PRR.

Two recent reviews of therapy for people with $\mathrm{CP}$ both highlight the importance of physical conditioning for this group. Damiano (2006) recommends using training protocols and practicing activities that involve moving the legs in cyclical movement patterns. Palisano, Snider, and Orlin (2004) highlight the importance of programmes that emphasise lifelong fitness, weight control, and conditioning. Petra-running is an important new development and it offers further choice in the means of physical conditioning for people with CP. It can be a key component in the kinds of programmes recommended by these two reviews.

There is an important question about how a repetitive activity such as Petra-running may influence the movement pattern of persons with $\mathrm{CP}$ over the longer term. This is particularly important when considering younger children with $\mathrm{CP}$. These children may still be developing the movement patterns they use in functional activities. When a new activity such as Petra-running is introduced, it is important to monitor for any negative changes in the child's quality of movement. It is best that a child's physiotherapist is aware of this new activity and that there is a good working relationship between a child's physiotherapist and the sports club where they train in Petra-running. These concerns regarding younger children will apply to a lesser extent to teenagers and adults who commence the sport. There is less likelihood that their movement patterns in functional activities will change, but there is a possibility that muscles used in the
Petra-running action could become tighter over time.

Several issues need to be investigated regarding Petra-running. One important area of concern is the risk of overuse injuries in Petra-running. Overuse injuries are seen in sports where there is a repetitive action (Corrigan and Maitland, 1994), and Petrarunning is likely to be similar in this regard. Certain orthopaedic problems such as equinus, midfoot breaking, and hip joint subluxation are seen in persons with $\mathrm{CP}$. These problems may predispose to certain types of overuse injuries. Investigation is also needed to learn how the position settings on a PRR can be optimally adjusted to the runner. Factors such as saddle-height, saddle fore-aft position, trunk support position, and handlebar position will all influence the economy of movement of the PRR. Optimising mechanical efficiency will enable runners to run at a faster pace or to maintain a similar pace for a longer time expending less energy. There is a potential role for Petrarunners to train as members of mainstream athletics clubs. The resources and planning necessary for this, and the attitudes of various parties in this, need to be explored.

Three important shortcomings of this study should be mentioned. First, the small sample size reduces the statistical power of the study drastically. As no more PRR athletes would be recruited in Belgium, an international approach should be considered. Second, to fully understand the advantages and disadvantages of PRR, this mode of propulsion should be compared in the same population under similar external conditions using alternative devices such as a tricycle. Finally, to clarify eventual adverse effects of PRR on movement quality, it is important to also analyze the impact of PRR during fatigue on posture and movement of trunk, head and upper extremities.

\section{REFERENCES}

Bell, E., \& Watson, A. (1986). The prevention of positional deformity in cerebral palsy. Physiotherapy Practice, 2, 86-92. 
Bobath, B. (1990). Adult hemiplegia: evaluation and treatment. $3^{\text {rd }}$ ed. London: William Heinemann Medical Books.

Blundell, S.W., Shepherd, R.B., Dean, C.M., \& Adams, R.D. (2003). Functional strength training in cerebral palsy: a pilot study of a group circuit training class for children aged 4-8 years. Clinical Rehabilitation, 17, 4857.

Chappel, R. (2002). Sports for persons with cerebral palsy. Course notes for European Masters Degree in Adapted Physical Activity, Katholieke Universiteit Leuven. Belgium.

Cooper, C.B., \& Storer, T.W. (2001). Exercise testing and interpretation: a practical approach. Cambridge, UK: Cambridge University Press.

Cooper, R.A., Quatrano, L.A., Axelson, P.W., Harlan, W., Stineman, M., Franklin, B.A., Krause, J.S., Bach, J., Chambers, H., Chao, E.Y.S., Alexander, M., \& Painter, P. (1999). Research on physical activity and health among people with disabilities: a consensus statement. Journal of Rehabilitation Research and Development, 36, 142-154.

Corrigan, B. \& Maitland, G.D. (1994). Musculoskeletal and Sports Injuries. Oxford: Butterworth-Heinemann.

Damiano, D.L. (2006). Activity, Activity, Activity: Rethinking our physical therapy approach to cerebral palsy. Physical Therapy, 86, 1534-1540.

Darrah, J., Wessel, J., Nearingburg, P., \& O'Connor M. (1999). Evaluation of a community fitness program for adolescents with cerebral palsy. Pediatric Physical Therapy, 11, 18-23.

Dodd, K.J., Taylor, N.F., \& Damiano, D.L. (2002). A systematic review of the effectiveness of strength training programs for people with cerebral palsy. Archives of Physical Medicine and Rehabilitation, 83, 1157-1164.

Fowler, E.G., Ho, T.W., Nwigwe, A.I., \& Dorey F.J. (2001). The effect of quadriceps femoris muscle strengthening exercises on spasticity in children with cerebral palsy. Physical Therapy, 81, 1215-1223.
Hoofwijk, M., Unnithan, V., \& Bar-OR, O. (1995). Maximal treadmill performance of children with cerebral palsy. Pediatric Exercise Science, 7, 305-313.

Lundberg, A., \& Pernow, B. (1970). The effects of physical training on oxygen utilisation and lactate formation in the exercising muscle of adolescents with motor handicaps. Scandinavian Journal of Clinical Laboratory Investigation, 26, 89-96.

Miller, G.J.T., \& Light, K.E. (1997). Strength training in spastic hemiparesis: should it be avoided? NeuroRehabilitation, 9, 17-28.

Morton, J.F., Brownlee, M., \& McFadyen, A.K. (2005). The effects of progressive resistance training for children with cerebral palsy. Clinical Rehabilitation. 19, 283-289.

Palisano, R.J., Snider, L. M., \& Orlin, M.N. (2004). Recent advances in physical and occupational therapy for children with cerebral palsy. Seminars in Pediatric Neurology, 11, 66-77.

Richter, K.J., Gaebler-Spira, D., \& Mushett, C.A. (1996). Sport and the person with spasticity of cerebral origin. Developmental Medicine and Child Neurology, 38, 867870.

Rimmer, J.H. (2001). Physical fitness levels of persons with cerebral palsy. Developmental Medicine and Child Neurology, 43, 208-212.

Sjodin, B., Schele, R., Karlsson, J., Linnarsson, D., \& Wallensten, R. (1982). The physiological background of onset to blood lactate accumulation. In P. Komi (Ed) Exercise and Sport Biology. International Series on Sport Sciences, Vol. 12. Illinois, USA: Human Kinetics.

Unnithan, V.B., Clifford, C., \& Bar-OR, O. (1999). Evaluation by exercise testing of the child with cerebral palsy. Sports Medicine, 26, 239-251.

Wind, W.M., Schwend, R. M., \& Larson, J. (2004). Sports for the physically challenged child. Journal of the American Academy of Orthopedic Surgeons, 12, 126-137.

Corresponding author's address: yves.vanlandewijck@faber.kuleuven.be 


\section{KINESIOLOGISCHE UND METABOLISCHE REAKTIONEN VON PERSONEN MIT CEREBRALPARESE AUF AUSDAUERBELASTUNG AUF EINEM PETRA RENNRAD}

(Resümee)

Die Absicht dieser Studie war es zu untersuchen, ob die Leistung und die metabolische Reaktion von Sportlern mit Cerebralparese (CP) auf eine submaximale Dauerbelastung auf einem Petra Rennrad (PRR) mit deren Klassifikation nach CP-ISRA konform ging. Des Weiteren wurde der Einfluss der Ermüdung auf die Qualität der Antriebsbewegung bewertet. Neun Sportler mit CP der CP-ISRA Klasse CP1 bis CP6 nahmen an einem 12 Minuten Cooper Test unter Verwendung eines PRR teil. Dabei wurden den gesamten Test über Veränderungen der Herzfrequenz sowie Blutlaktat und Tempo jede Minute beobachtet. Die Ergebnisse zeigten, dass die Herzfrequenz sofort hoch anstieg (im Durchschnitt über 160 nach der ersten Minute) und den Test über auf diesem Niveau blieb. Die Blutlaktat-Konzentration nahm nach einem kurvenlinearen Muster zu, war aber interindividuell sehr verschieden. Die Analyse der Video-Aufzeichnung zeigte, dass die Probanden ein sehr konstantes Bewegungsmuster (Schrittlänge, Schrittfrequenz) einhielten, auch als sie in der späten Phase des Cooper-Tests ermüdeten. Die Resultate demonstrierten die Limitierungen für den Gebrauch der CP-ISRA Klassen für PRR Wettkämpfe klar. Es konnte kein ungünstiger Einfluss auf die Qualität der Antriebsbewegung bei andauernder submaximaler Belastung auf dem PRR nachgewiesen werden.

SCHLÜSSELWÖRTER: Petra Rad, Cerebralparese, Cooper Test, Herzfrequenz, Paralympics.

\section{REPONSES METABOLIQUES ET CINESIOLOGIQUES DE PERSONNES INFIRMES MOTRICES CEREBRALES LORS D'EXERCICE PROLONGE SUR TRICYCLE \\ (Résumé)}

L'objectif de cette étude consistait à vérifier si la performance et les réponses métaboliques d'athlètes infirmes moteurs cérébraux (IMC) mesurées lors d'un exercice sous-maximal sur tricycle étaient en conformité avec leur classification CP-ISRA. De plus, a été évalué l'impact de la fatigue sur la qualité du mouvement de propulsion. Au total, neuf athlètes IMC appartenant aux classes $\mathrm{CP} 1$ à $\mathrm{CP} 6$ selon la classification CP-ISRA, ont réalisé un test Cooper de 12 minutes utilisant un tricycle. Les évolutions de la fréquence cardiaque, de la lactatémie ainsi que le nombre de pas par minute ont été évaluées tout au long du test. Les résultats ont montré une augmentation immédiate de la fréquence cardiaque atteignant d'importantes valeurs (une moyenne au-delà de 160 battements par minute après la première minute) maintenues au cours du test. La lactatémie a augmenté de manière curvilinéaire mais était sujette à des variations interindividuelles. L'analyse des enregistrements vidéo a révélé un pattern de mouvement stable (longueur et fréquence de pas) même après l'apparition de la fatigue. Les résultats démontrent clairement les limitations de l'utilisation de la classification CP-ISRA pour les compétitions de tricycle. Aucune évidence n'a été conclue montrant un impact défavorable d'un exercice sous-maximal prolongé en tricycle sur la qualité du mouvement de propulsion.

MOTS CLEFS: Tricycle, Infirmité Motrice Cérébrale, test de Cooper, fréquence cardiaque, Jeux Paralympiques. 